\title{
LA INCORPORACIÓN DEL PAISAJE A LA PLANIFICACIÓN TURÍSTICA. ANÁLISIS DE LA ESTRATEGIA DE TURISMO SOSTENIBLE DE ANDALUCÍA ${ }^{1}$
}

\author{
Enrique Santos-Pavón \\ Alfonso Fernández-Tabales \\ Olga Muñoz-Yules \\ Universidad de Sevilla
}

\section{RESUMEN}

Las interrelaciones entre turismo y paisaje, pese a su trascendencia para ambas temáticas, han sido poco tratadas con enfoque científico, y sólo recientemente se está incorporando el paisaje en los trabajos de planificación turística. Este artículo profundiza en las bases teóricas de esa interrelación y analiza en detalle el tratamiento del paisaje en una experiencia real de planificación de destinos, los programas derivados de la Estrategia de Turismo Sostenible de Andalucía; tanto en lo relativo a la consideración del paisaje como recurso turístico, como en lo referido a las actuaciones concretas presupuestadas con incidencia paisajística.

Palabras clave: Turismo; planificación turística; paisaje; Estrategia de Turismo Sostenible de Andalucía.

The inclusion of the landscape aspects in the tourism planning. The analysis of the Andalusian sustainable tourism strategy

Recibido: 14 de enero de 2015

Devuelto para su revisión: 26 de mayo de 2015

Aceptado: 18 de diciembre de 2015

Departamento de Geografía Física y Análisis Geográfico Regional. Universidad de Sevilla. C/ Doña María de Padilla, s/n. 41004 SEVILLA (España).E-mail: aftabales@us.es

1 Este artículo es resultado de los trabajos realizados en el Proyecto de Investigación «Paisaje urbano y turismo: percepciones, conflictos y tratamiento normativo. Estudios de caso en las ciudades de Sevilla y Málaga», financiado por el Campus de Excelencia Internacional en Patrimonio «Patrimoniun 10». Convocatoria de ayudas para Programas de generación de investigación de referencia internacional. 


\begin{abstract}
The relations between tourism and landscape, in spite of the importance for both topics, have been scarcely analyzed with a scientific approach, and only recently the landscape has begun to be incorporated to the tourism planning. This article studies the theoretical basis of this relation and analyses in detail the treatment of the landscape in a real experience of tourism destinations planning: the programs resulting of the Sustainable Tourism Strategy of Andalusia. In these documents, it is analyzed the consideration of the landscape as a tourism resource, as well as the landscape purposes considered in the financial framework of the programs.
\end{abstract}

Keywords: Tourism; Tourism Planning; Landscape; Sustainable Tourism Strategy of Andalusia.

\title{
1. INTRODUCCIÓN: LAS INTERRELACIONES ENTRE TURISMO Y PAISAJE
}

El paisaje, entendido como «cualquier parte del territorio, tal como es percibida por las poblaciones, cuyo carácter resulta de la acción de factores naturales y/o humanos y de sus interrelaciones» (Convención Europea del Paisaje), es actualmente aceptado no sólo como un elemento patrimonial de primer orden (Zoido y Venegas (Coord), 2002; Scazzosi, 2004; Fernández Salinas y Silva, 2008) sino también como uno de los recursos turísticos esenciales, pues la apreciación y disfrute estético de entornos diferentes al escenario de la vida cotidiana representa una de las motivaciones fundamentales del viaje turístico (Bardón, 1991; Nogué, 1992; De Aranzabal, Schmitz et alt., 2009); pudiendo llegar a ser la motivación principal, que por sí misma atraiga a los flujos de demanda en el caso de paisajes de excepcional calidad.

Esta función esencial, en la que se puede incluir el papel decisivo del paisaje en la creación de la imagen transmitida al turista (Antón, 2010), se ve revalorizada aún más ante los cambios operados en las últimas fases de desarrollo del sistema turístico, en las que la calidad territorial y paisajística (en tanto que indicador perceptible del equilibrio o armonía entre los factores físicos y humanos que actúan sobre un territorio) se muestra repetidamente como una de las exigencias determinantes en el proceso de elección del destino (Requejo, 2007); por lo que la degradación de la misma incidirá inevitablemente en la pérdida de competitividad y rentabilidad del espacio afectado.

Así pues, la calidad territorial, de la que el paisaje es resultado e imagen (Foronda y Galindo, 2012), se configura como un factor esencial de competitividad de los destinos en el escenario turístico global, en el que destinos maduros como los españoles no pueden sustentar su capacidad de atracción a partir de precios reducidos del producto, sino mediante estrategias de cualificación, singularidad y diferenciación; consecuentemente, el deterioro de la calidad territorial y paisajística representa la erosión a medio-largo plazo de las bases en las que se sustenta la actividad en dichos destinos.

Esta temática es especialmente trascendente en el caso de los usualmente denominados paisajes turísticos, es decir, aquéllos que presentan, o deberían presentar, una marcada dimensión lúdica y estética diferenciada de los paisajes residenciales o productivos; y en los que, a diferencia de éstos otros paisajes más usuales, la percepción por parte de 
población visitante resulta imprescindible (sin que ello se oponga a la de la población residente) en el proceso de valoración y conformación simbólica de los mismos.

Pese a lo anteriormente expresado, las relaciones entre turismo y paisaje han constituido un marco notablemente conflictivo desde los inicios de la actividad (Gómez Aguilera, 2001; González Pérez, 2003; Ramón y Canos, 2010; Mercado, 2015). De hecho, puede afirmarse que los usos turísticos han significado el principal factor de transformación paisajística de las últimas décadas en el mundo desarrollado, y en un sentido negativo en una proporción abrumadora de los casos. Como problemas o impactos más generalizados pueden citarse:

- La alteración absoluta de paisajes litorales, a través de procesos de urbanización muy cercanos a la línea de costa, y con morfologías constructivas, alturas y volumetrías que constituyen barreras infranqueables a la permeabilidad visual (Galacho y Luque, 2000; Rodríguez Chumillas, 2008).

- La degradación de la imagen tradicional de los cascos históricos en los núcleos de población, en los que el paisaje o la escena urbana constituye uno de los principales elementos de identificación y factor de atracción; degradación derivada de la propia masificación de la afluencia turística, o de la implantación de tipologías inadecuadas en elementos visuales vinculados a la actividad (señalización, mobiliario urbano, anuncios exteriores o estética general deficiente en los establecimientos comerciales dirigidos a los visitantes, etc.) (Zukin, 1998; Campos y López Sánchez, 2006).

- El deterioro visual de áreas o hitos de elevada potencialidad paisajística en espacios rurales y de montaña, a partir de la diseminación de edificaciones o instalaciones vinculadas a prácticas turísticas (alojamientos, segundas residencias, remontes, centros deportivos, nuevas carreteras a focos turísticos, etc.) (Faus e Higueras, 2000; Aledo, 2008; Ramón y Canos, 2011; Sánchez del Árbol, 2012).

En definitiva, y como han señalado diversos autores (Diener, 2007; Córdoba, 2009; Gottdiener, Simpson y Schmid, 2010; Antón, 2010; Vera (Coord), 2011), los efectos negativos de esta relación turismo-territorio-paisaje, se pueden sintetizar en dos fenómenos, la estandarización, por una parte, entendida como la reproducción de paisajes seriados generados por la industria turística, carentes de identidad propia, afectados por la «urbanalización» según la ya célebre expresión de Francesc Muñoz (2006), precisamente en un momento en el que la singularidad se afirma como la principal estrategia de diferenciación del destino; y la espectacularización, por otra, consistente en la transformación del paisaje previo para hacerlo presumiblemente más atractivo, en aras de ajustarse a las expectativas generadas en la demanda.

Sin embargo, pese al notable potencial de conflicto que encierra esta relación turismopaisaje, es igualmente evidente lo inevitable del diálogo entre ambas realidades, o expresado en la muy citada frase de Urry (2005) «el consumo de lugares en tanto que paisajes es, de hecho, nuestro destino y nuestro dilema. No puede ser evitado». El desafío consiste en intervenir sobre los inevitables procesos de transformación paisajística derivados del turismo, de forma que puedan ser canalizados conservando el carácter de los paisajes afectados (entendiendo por tal expresión el conjunto de rasgos esenciales y diferenciales que los singularizan en cada caso), maximizando su capacidad de generación de rentas y empleos sin convertirlos en objeto de una mercantilización degradadora. Para ello se hace necesario 
analizar dicha relación en la práctica, obteniendo una comprensión detallada de los factores, procesos y agentes que la explican, evaluando sus efectos y planteando indicadores de los mismos, y finalmente proponiendo instrumentos y estrategias para la intervención en dichos procesos y la prevención de impactos negativos (Dos Santos Pires, 2011).

En este sentido, y es un tema de extrema importancia para la regeneración de la calidad territorial de espacios singulares, el turismo puede desempeñar un importante papel, de hecho ya ha comenzado a hacerlo, como factor incidente en la regeneración de paisajes degradados (bien por la propia actividad turística, por otras o por desuso), en tanto que instrumento financiador de intervenciones de recuperación o conservación. Pudiendo aportarse como ejemplos la recuperación de cascos históricos deteriorados; la regeneración de paisajes mineros o industriales, revalorizados como nuevos recursos turísticos (Llurdes, 1994); o los procesos de recualificación paisajística planteados en destinos turísticos consolidados, dentro de las estrategias vigentes de actualización competitiva de éstos.

Por último, a la hora de expresar efectos positivos vinculados al turismo en la temática de la calidad territorial, debe citarse necesariamente el protagonismo ejercido por aquél en la rentabilización económica del paisaje. En efecto, al margen de sus valores estéticos, emocionales o identitarios, el paisaje encuentra una valoración en términos económicos a través de su concepción como recurso turístico; con lo que el turismo, y ello puede ser la consecuencia pragmática más trascendente de todo lo expresado, se convierte así en un sólido argumento para la adopción de políticas paisajísticas por parte de las administraciones públicas, parte indispensable en el objetivo global de mejora de la calidad territorial de los espacios-destino.

De todo lo anterior se deduce la necesidad de incluir la temática paisajística en los procesos de planificación turística a todas las escalas (De Aranzabal, Schmitz et alt., 2009), en los que hasta el momento ha estado prácticamente ausente (Vera (Coord), 2011), en parte por lo relativamente novedoso de la adopción de políticas paisajísticas desde las administraciones públicas (Zoido y Venegas (Coord), 2002; Mata y Tarroja, 2006), y en parte por la propia complejidad metodológica de dicha inclusión (Acevedo y Del Risco, 2000; Dos Santos Pires, 2011); sin embargo, de forma progresiva, las prácticas de las políticas turísticas van abriéndose a la cuestión del paisaje, como se abordará en este artículo para el caso de la Comunidad Autónoma de Andalucía.

\section{OBJETIVOS Y METODOLOGÍA ${ }^{2}$}

El objetivo general de este artículo es analizar la incorporación del paisaje en la práctica de la planificación turística. Dicho objetivo general se buscará a partir del cumplimiento de los siguientes objetivos específicos:

- Realizar una aproximación teórica a las interrelaciones existentes entre paisaje y actividad turística.

- Revisar, a modo de referencia para otros ámbitos de gestión pública, los precedentes de tratamiento conjunto del paisaje y el turismo en las políticas de la administración autónoma andaluza.

2 Se ha decidido dedicar un apartado específico a las fuentes de información empleadas para la elaboración de este artículo, concretamente el posterior apartado 4, en el que se realiza una presentación amplia de los Programas de Turismo Sostenible derivados de la Estrategia de Turismo Sostenible de Andalucía. 
- Proponer una metodología de análisis del tratamiento del paisaje en la planificación turística.

- Aplicar la metodología propuesta al caso de los Programas derivados de la Estrategia de Turismo Sostenible de Andalucía, llegando a conclusiones acerca de cómo puede enfocarse dicho tratamiento.

La metodología empleada en la investigación que ha dado lugar al artículo ha seguido varias fases enlazadas progresivamente:

En primer lugar se realizó una revisión bibliográfica y documental sobre las relaciones teóricas y conceptuales entre turismo y paisaje, por una parte, y sobre los precedentes administrativos de tratamiento conjunto de ambas temáticas en las políticas públicas, especialmente en el caso andaluz, por otra.

A continuación se procedió al análisis detallado de la totalidad de Programas de Turismo Sostenible aprobados hasta el momento en aplicación de la Estrategia de Turismo Sostenible de Andalucía, 31 documentos en total. Dicho análisis se concretó en la cumplimentación para cada Programa de una ficha inicial (figura 1) en la que se recogían todos los aspectos relacionados con el paisaje observados en los documentos analizados, así como otros elementos destacables, como la información relativa a los agentes promotores, el ámbito de actuación, etc.

\section{Figura 1}

\section{APARTADOS QUE COMPONEN LA FICHA INICIAL CUMPLIMENTADA PARA CADA PROGRAMA DE TURISMO SOSTENIBLE ANALIZADO}

\begin{tabular}{|l|}
\hline \multicolumn{1}{|c|}{ Ficha inicial para sistematizar la información extraída de los PTS } \\
\hline \multicolumn{1}{|c|}{ Apartados } \\
\hline 1. Identificación de los agentes promotores: públicos y privados. \\
\hline 2. Ámbito de actuación: delimitación y caracterización general. \\
\hline $\begin{array}{l}\text { 3. Aspectos metodológicos y formales reseñables del documento presentado: formulación del plan } \\
\text { (esquema metodológico), estructura de contenidos, elementos gráficos, programación temporal y } \\
\text { financiera, etc. }\end{array}$ \\
\hline 4. ¿Se utiliza el término paisaje en el documento? ¿Se utilizan otros términos análogos? \\
\hline $\begin{array}{l}\text { 5. ¿Aparece el paisaje sólo como referencia descriptiva, por ejemplo en la parte informativa del } \\
\text { documento a la hora de presentar el ámbito de actuación? }\end{array}$ \\
\hline 6. ¿Se considera el paisaje como recurso turístico, por ejemplo en los diagnósticos que se aporten? \\
\hline $\begin{array}{l}\text { 7. ¿Aparecen productos turísticos concretos vinculados al paisaje, por ejemplo, itinerarios, rutas, } \\
\text { actividades de observación, etc.? }\end{array}$ \\
\hline $\begin{array}{l}\text { 8. ¿Existen propuestas de inversión que tengan por objeto o que incidan en el paisaje? ¿Qué tipo de } \\
\text { actuaciones? (embellecimiento de hitos o entornos, miradores, paneles panorámicos, etc.) }\end{array}$ \\
\hline $\begin{array}{l}\text { 9. ¿Existen diferencias significativas a la hora de considerar el paisaje entre los diferentes tipos de } \\
\text { ámbitos: rurales, urbanos, litorales, etc.? }\end{array}$ \\
\hline $\begin{array}{l}\text { 10. ¿Se puede establecer algún tipo de relación entre las propuestas paisajísticas planteadas en los } \\
\text { Programas analizados y las contempladas en el Plan General de Turismo de Andalucía? }\end{array}$ \\
\hline 11. Otros aspectos de especial interés del documento. \\
\hline
\end{tabular}

Fuente: elaboración propia. 
Posteriormente, esta información ha sido nuevamente tratada con el fin de concretar y homogeneizar la información extraída de cada Programa en una segunda ficha más específica, ofrecida en la figura 2. Finalmente, el contenido de todas las fichas cumplimentadas fue volcado en una base de datos para facilitar la ordenación y el análisis de la información.

\section{Figura 2}

APARTADOS QUE COMPONEN LA FICHA FINAL ELABORADA PARA CADA PROGRAMA ANALIZADO

Ficha final de síntesis de la información extraída de los PTS

Apartados

ASPECTOS GENERALES DEL DOCUMENTO

\begin{tabular}{|l|}
\hline 1. Promotor \\
\hline 2. Ámbito de actuación \\
\hline 3. Presupuesto total \\
\hline TRATAMIENTO DEL PAISAJE EN EL DOCUMENTO \\
\hline 4. Consideración del paisaje en los apartados de información y diagnóstico \\
\hline $\begin{array}{l}\text { 5. Consideración del paisaje en el apartado propositivo e inversión dedicada a acciones } \\
\text { y proyectos vinculados al paisaje }\end{array}$ \\
\hline OTROS ASPECTOS DE INTERÉS DEL DOCUMENTO \\
\hline
\end{tabular}

Fuente: elaboración propia.

Para esta labor de síntesis de la información ha sido de gran ayuda que todos estos Programas estén sujetos a una forma específica predeterminada (la Guía de Apoyo establecida por la Consejería), puesto que se presentan de manera homogénea. Aunque por otra parte, esta forma tan detallada prefijada para los Programas, junto con el hecho de que los objetivos y las acciones concretas a proponer deben ser las expresadas en la Orden 9 de Noviembre, hace que sea más complicado analizar hasta qué punto existe o no una intencionalidad en tratar el paisaje y el grado de dicha intencionalidad.

Respecto al presupuesto asignado a las diferentes acciones también existe la dificultad de que no en todos los planes aparecen detalladas todas y cada una de las actuaciones concretas que se realizarán en el plan, puesto que estas actuaciones pueden ser concretadas con posterioridad, en el denominado Plan de Acción anual a presentar a la Consejería. Por ello, y cuando ha resultado posible, si se conocía la cuantía específica de la actuación concreta vinculada al paisaje, se ha tomado dicha cantidad; en los casos en los que estas actuaciones concretas se desconocían en su totalidad o bien su cuantía, se ha considerado el presupuesto total asignado en el Programa para las Acciones Específicas que se han estimado como vinculadas al paisaje (reflejadas en la figura 3), del total de Acciones Específicas posibles establecidas por la Guía de Apoyo. 


\section{Figura 3 \\ ACCIONES ESPECÍFICAS DE LOS PROGRAMAS DE TURISMO SOSTENIBLE VINCULADAS AL PAISAJE}

\section{Acciones específicas vinculadas al paisaje}

a) Creación de producto turístico o mejora del existente.

a.3. Implantación de rutas turísticas.

a.5. Puesta en valor de vías verdes.

c) Creación, mantenimiento y mejora del espacio turístico:

c.1. Embellecimiento de los entornos y accesos a los recursos incluyendo eliminación de cableado, recuperación de elementos de la arquitectura tradicional, embellecimiento de vías en cascos históricos así como el soterramiento de contenedores de residuos.

c.2. Establecimiento y mejora de los sistemas de señalización turística.

c.4. Creación y recuperación de miradores paisajísticos.

c.5. Recuperación y tratamiento paisajístico.

Fuente: elaboración propia a partir de la Orden de 9 de noviembre de 2006, por la que se articula la Estrategia de Turismo Sostenible de Andalucía.

Se ha descartado introducir el objetivo c.6. Rehabilitación o restauración, para su dedicación al uso turístico, de inmuebles con más de 50 años de antigüedad y con algún significado histórico o que refleje la tipología constructiva representativa del lugar, recuperando su entorno o memoria histórica, porque aunque tenga incidencia en el paisaje urbano, su objetivo principal está orientado a la rehabilitación y conservación del patrimonio.

Tras este trabajo de levantamiento de información, ordenación y análisis de la misma, se procedió a proponer una categorización de los Programas en función de los niveles de consideración y tratamiento del paisaje en los apartados de información y diagnóstico de los mismos, clasificándolos en tres categorías (véase posteriormente la figura 5). Y se propuso igualmente una clasificación temática de los contenidos paisajísticos más habituales en los citados apartados, estableciéndose siete ámbitos temáticos diferenciados (véase posteriormente la figura 6).

A continuación se evaluó la atención y la dedicación «real» prestada al paisaje en los documentos, a través del análisis de las propuestas concretas formuladas en los planes y, sobre todo, de la asignación financiera a las acciones y proyectos vinculados al paisaje. A raíz de ello se elaboró una jerarquización de los Programas y de los distintos tipos de acción vinculadas al paisaje, en función de la dedicación financiera a estas últimas (véanse posteriormente los cuadros 2 y 3 ).

Finalmente se procedió al establecimiento de los resultados de la investigación y la redacción de las conclusiones finales de la misma. 


\section{PRECEDENTES DE INTERRELACIÓN ENTRE TURISMO Y PAISAJE EN LA ADMINISTRACIÓN PÚBLICA ANDALUZA}

A la hora de buscar precedentes acerca de un tratamiento conjunto de las temáticas paisajísticas y turísticas en la Administración Autónoma Andaluza, es necesario hacer mención a dos documentos aprobados por la misma, en primer lugar, las consideraciones vinculadas al paisaje presentes en el Plan General de Turismo Sostenible de Andalucía 2008-2011 y, en segundo lugar, las referencias a la actividad turística contenidas en la Estrategia de Paisaje de Andalucía.

Como primer precedente relevante, el Plan General de Turismo Sostenible de Andalucía 2008-2011, documento que se sitúa en la cúspide de la pirámide de la planificación turística andaluza, ya que de él derivan las políticas turísticas de la Junta, aborda la temática paisajística en buena parte de sus contenidos, entre ellos algunos de los más relevantes. Por ejemplo, a nivel declarativo, la primera de las Orientaciones Estratégicas que constituyen los grandes ejes vertebradores del Plan, queda redactada de la siguiente forma: «Orientación Estratégica A.1. Fomentar el desarrollo basado en la diferencia a partir del reforzamiento de la identidad del espacio turístico basada en el patrimonio natural, cultural y paisajístico» (negrillas añadidas al original).

Y desde el punto de vista operativo, se crea una nueva figura de planificación, hasta entonces inexistente, centrada en la cuestión paisajística, las denominadas «Acciones Semilla en el Paisaje». Esta figura aparece como Instrumento 7.2.b, dentro del epígrafe de «Iniciativas de gestión en espacios turísticos». Su finalidad expresa consiste en crear experiencias piloto que muestren a los operadores criterios de gestión del paisaje desde el punto de vista turístico, siendo en la práctica intervenciones experimentales que proporcionen criterios a otras políticas y a los agentes transformadores del medio para optimizar el manejo del paisaje desde el punto de vista turístico. Sus contenidos se concretan en la Medida 1.5, al afirmar que: «Se considera prioritaria la puesta en marcha de actuaciones dirigidas a la identificación de «zonas semilla» para la recualificación del paisaje urbano litoral... (y) se fomentará el desarrollo de intervenciones, de carácter demostrativo, basadas tanto en la adecuación de hitos y elementos singulares de valor en el medio, como en la implantación de tipologías de tratamiento del paisaje concretas que puedan servir de referencia en la aplicación de otras políticas en esta materia» (negrillas añadidas al original).

De esta forma, cabe destacar lo innovador de la propuesta, sustentada en la generación de experiencias-piloto de urbanismo turístico litoral acordes con las exigencias paisajísticas, que puedan servir de modelos de actuación a los agentes privados. Sin embargo, hay que señalar que transcurrido el periodo de vigencia del Plan estas Acciones Semilla no se han desarrollado, en buena parte por las restricciones presupuestarias atravesadas en los últimos años, si bien no se descarta que puedan ser retomadas en el futuro.

Como segundo precedente de interés, la Estrategia de Paisaje de Andalucía (aprobada por la Junta de Andalucía el 6 de marzo de 2012), representa el documento base para las políticas de paisaje en la Comunidad Autónoma, integrando las políticas públicas orientadas a conseguir su conservación y mejora, y promoviendo expresamente la colaboración activa de las Consejerías responsables. Para su concreción, se optó por la forma jurídica de una Estrategia, que es un documento no vinculante jurídicamente pero que expresa el consenso 
político en el que se establece un compromiso voluntario de las partes firmantes, en este caso las diferentes Consejerías con competencias incidentes en la materia (entre ellas la Consejería de Turismo, Comercio y Deporte), los Entes Locales y representantes de la sociedad civil.

La Estrategia se fundamenta en el desarrollo de siete objetivos de calidad paisajística: impulsar la recuperación y mejora paisajística del patrimonio natural, impulsar la recuperación y mejora paisajística del patrimonio cultural, cualificar los espacios urbanos, cualificar los paisajes asociados a actividades productivas, cualificar las infraestructuras de transporte, energía y telecomunicaciones, implementar instrumentos de gobernanza paisajística y potenciar la sensibilización, la educación y la formación en materia de paisaje. Para cada uno de estos objetivos se definen líneas estratégicas que se desagregan en actuaciones de diverso tipo.

Desde el punto de vista turístico, los contenidos más relevantes se ubican en el seno del Objetivo 4 «Cualificar los paisajes asociados a actividades productivas» y, dentro de las Líneas Estratégicas que lo desarrollan, en la Línea 4.2, denominada «Paisaje y actividades turísticas». Lo más significativo de lo establecido en la misma se subdivide en dos ámbitos: Inserción en Instrumentos de Planificación y Gestión; y Desarrollo de Programas de Acción.

En lo referente a la Inserción en Instrumentos de Planificación y Gestión, destacan aspectos como:

- Incorporación y desarrollo de objetivos y criterios paisajísticos en los instrumentos de diseño y planificación la política turística (Plan General de Turismo; Marcos Estratégicos para la Ordenación de los Recursos y las Actividades Turísticas; Planes Turísticos de Grandes Ciudades; y Estrategia de Turismo Sostenible de Andalucía (a cuyo análisis se dedicará el resto de este artículo).

- Reforzamiento de la consideración del paisaje en los Planes de Ordenación del Territorio y el planeamiento urbanístico de ámbitos litorales.

- Aplicación de la Carta Europea de Turismo Sostenible en los espacios naturales: inclusión de criterios paisajísticos.

Por lo que respecta al Desarrollo de Programas de Acción, se especifican los siguientes aspectos:

- Incorporación y desarrollo de objetivos y criterios paisajísticos en los programas de acción de la política turística (Programas Específicos de Turismo; Ayudas a Municipios Turísticos; y Programas de Recualificación de Destinos).

- Desarrollo de nuevos programas de recualificación de destinos turísticos maduros, incorporando criterios y actuaciones paisajísticas.

- Introducción de requisitos paisajísticos en las ayudas a municipios turísticos.

- Recomendaciones paisajísticas para los campos de golf.

- Guía de integración paisajística de alojamientos turísticos en espacios naturales.

Sin entrar a analizar en profundidad estas determinaciones, ya que no es este artículo el contexto para ello, sí cabe señalar que en la práctica se asume el compromiso de introducir la temática paisajística en la práctica totalidad de los instrumentos de planificación de la 
Consejería de Turismo, así como en sus principales acciones vinculadas de forma directa con los destinos. Igualmente, de cara a los objetivos de este artículo, destaca que se señala expresamente la necesidad de introducir objetivos y criterios paisajísticos en la Estrategía de Turismo Sostenible de Andalucía, tratada en los siguientes epígrafes.

\section{LA ESTRATEGIA DE TURISMO SOSTENIBLE DE ANDALUCÍA COMO EXPERIENCIA DE PLANIFICACIÓN}

La Estrategia de Turismo Sostenible (en la que se centra este artículo) es un instrumento de la Consejería de Turismo, Comercio y Deporte creado con la finalidad declarada de «favorecer un desarrollo turístico sostenible de Andalucía a través de un sistema de planificación estratégica desde el territorio (ascendente y coparticipado), llevado a cabo por los actores turísticos de la zona, para que exista respeto hacia los objetivos de desarrollo turístico diseñados por los mismos» (Orden de 9 de Noviembre de 2006). Este instrumento está recogido en el Plan General de Turismo Sostenible de Andalucía 2008-2011, siendo considerado en la categoría de programa de iniciativa local con incidencia subregional.

Este instrumento se regula a partir de la Orden de 9 de noviembre de 2006, por la que se articula la Estrategia de Turismo Sostenible de Andalucía y se instrumentan medidas para su desarrollo, publicada en BOJA el 13 de diciembre de 2006 (BOJA n ${ }^{\circ}$ 239). Posteriormente fue modificada por la Orden de 20 de febrero de 2008, por la Orden de 10 de diciembre de 2008, y finalmente por la Orden de 17 de diciembre de 2010; si bien estas modificaciones, que afectan sobre todo a cambios en los procedimientos para la concesión de subvenciones, no inciden en los objetivos de este artículo.

La Estrategia de Turismo Sostenible se aplica a través de los denominados Programas de Turismo Sostenible, que son los instrumentos de planificación turística en los que se recogen las acciones y proyectos concretos que se van a realizar en el territorio (y que son el objeto de esta investigación). Estos Programas de Turismo Sostenible engloban a su vez dos tipos de instrumentos: las Iniciativas de Turismo Sostenible, que están dirigidas a espacios con un importante potencial turístico que cuenten con recursos patrimoniales naturales o culturales de interés, con el fin de realizar un desarrollo equilibrado paralelo a la preservación de los mismos, o la incorporación de medidas de calidad; y las Iniciativas de Ciudades Turísticas, que están dirigida a crear redes de ciudades medias (cuya población de derecho se encuentre entre 15.000 y 100.000 habitantes), y a establecer o consolidar rutas culturales o itinerarios turísticos, para ofertar productos de turismo de naturaleza, cultural o monumental de gran atractivo.

Una figura de gran importancia en estos Programas son los Promotores de Turismo Sostenible, ya que estas entidades van a ser el nexo entre la Consejería de Turismo, Comercio y Deporte y el territorio objeto de aplicación. Es por ello que van a tener una doble función: como entidades colaboradoras y como agentes dinamizadores e impulsores de los Programas de Turismo Sostenible definiendo los objetivos, acciones y proyectos a desarrollar (art. 2). Se pueden constituir como Promotores de Turismo Sostenible las asociaciones sin ánimo de lucro, siempre y cuando también intervengan los ayuntamientos de los municipios del ámbito de intervención, y las mancomunidades, consorcios u otras asociaciones de municipios, y siempre que cuenten con la iniciativa privada de su ámbito. 
Este papel protagonista reservado a las entidades locales y los agentes privados es uno de los rasgos característicos de este instrumento, ya que se pretende que los Programas se generen y desarrollen de abajo a arriba y no por decisiones técnicas dimanadas de la administración autonómica; de hecho, una buena parte de dichas iniciativas se vincularon con Grupos de Desarrollo Rural precedentes con amplia experiencia en la aplicación de programas de desarrollo local.

Desde la aprobación de la Estrategia de Turismo Sostenible, se encuentran en fase de ejecución 31 Programas de Turismo Sostenible en toda Andalucía, en los que están implicados más de 400 municipios de interior y litoral. En conjunto, estos planes movilizarán una inversión total de 919,8 millones de euros, de los que la Consejería financia hasta un $60 \%$ de cada una de las Iniciativas.

Los Programas de Turismo Sostenible analizados para este artículo, con su año de aprobación y dotación presupuestaria, son los que se recogen en el cuadro 1.

En síntesis, se puede afirmar que estos Programas representan la experiencia de planificación de destinos turísticos más relevante en cuanto a extensión, movilización de recursos financieros e implicación de muy diversos agentes públicos y privados, de las aplicadas en Andalucía hasta el momento, y sin duda una de las más significativas a nivel estatal, si bien no es materia de este texto profundizar en su significado y resultados (para un análisis más global de estos documentos véase Hernández Ramírez, 2011 y Merinero et al. 2013). El resto del artículo se dedicará a analizar el tratamiento que el paisaje ha tenido en esta experiencia, como caso de estudio representativo de las nuevas tendencias en planificación turística.

\section{Cuadro 1}

\section{PROGRAMAS DE TURISMO SOSTENIBLE ANALIZADOS}

\begin{tabular}{|l|c|l|r|}
\hline \multicolumn{1}{|c|}{ PROGRAMA } & AÑO & PROVINCIAS IMPLICADAS & PRESUPUESTO $(€)$ \\
\hline 1. Comarca de Baza & 2007 & Granada & 10.793 .000 \\
\hline 2. Conjuntos Históricos Andalucía & 2007 & $\begin{array}{l}\text { Almería, Córdoba, Huelva y } \\
\text { Jaén }\end{array}$ & 14.516 .000 \\
\hline 3. Faja Pirítica Suroeste Peninsular & 2007 & Huelva y Sevilla & 42.000 .000 \\
\hline 4. Litoral de La Janda & 2007 & Cádiz & 15.925 .000 \\
\hline 5. Los Alcornocales & 2007 & Cádiz & 16.620 .000 \\
\hline 6. Poniente Granadino & 2007 & Granada & 9.632 .000 \\
\hline 7. Ruta del Tempranillo & 2007 & Córdoba, Sevilla y Málaga & 12.000 .000 \\
\hline 8. Sierra de Cádiz & 2007 & Cádiz & 7.707 .000 \\
\hline 9. Sierra de las Nieves & 2007 & Málaga & 8.125 .000 \\
\hline 10. Sierra Mágina & 2007 & Jaén & 11.330 .000 \\
\hline 11. Sierra Morena & 2007 & Jaén, Córdoba, Sevilla y Huelva & 17.323 .000 \\
\hline 12. Sierra Sur de Jaén & 2007 & Jaén & 4.900 .000 \\
\hline 13. Subbética Cordobesa & 2007 & Córdoba & 23.800 .000 \\
\hline 14. Turismo Naútico Bahía Cádiz & 2007 & Cádiz & 10.500 .000 \\
\hline 15. Vega del Guadalquivir & 2007 & Sevilla & 35.000 .000 \\
\hline
\end{tabular}




\begin{tabular}{|l|l|l|r|}
\hline 16. Valle del Guadalquivir & 2008 & Córdoba & 14.171 .000 \\
\hline 17. Altipl. Granada Paisajes Trogloditas & 2009 & Granada & 23.158 .000 \\
\hline 18. Campiña de Jerez & 2009 & Cádiz & 10.021 .000 \\
\hline 19. Ciudades Medias Centro Andalucía & 2009 & $\begin{array}{l}\text { Córdoba, Granada, Jaén, Mál. } \\
\text { y Sev. }\end{array}$ & 24.450 .000 \\
\hline 20. Costa Occidental de Huelva & 2009 & Huelva & 16.032 .000 \\
\hline 21. Guadalquivir a Caballo & 2009 & Córdoba, Sevilla y Cádiz & 16.877 .000 \\
\hline 22. La Axarquía & 2009 & Málaga & 168.807 .000 \\
\hline 23. Los Pedroches & 2009 & Córdoba & 18.023 .000 \\
\hline 24. Paisajes Mineros de Jaén & 2009 & Jaén & 5.000 .000 \\
\hline 25. Poniente de Almería & 2009 & Almería & 42.377 .000 \\
\hline 26. Villas Termales de Andalucía & 2009 & $\begin{array}{l}\text { Jaén, Almería, Cádiz, Gran. y } \\
\text { Málaga }\end{array}$ & 128.530 .000 \\
\hline 27. Andalucía en tus Manos & 2010 & Sevilla & 11.417 .427 \\
\hline 28. Costa Tropical de Granada & 2010 & Granada & 120.100 .000 \\
\hline 29. Doñana & 2010 & Huelva, Sevilla y Cádiz & 21.961 .000 \\
\hline 30. Úbeda y Baeza & 2010 & Jaén & 56.258 .000 \\
\hline 31. Vía Verde de la Sierra & 2010 & Cádiz y Sevilla & 2.450 .000 \\
\hline
\end{tabular}

Fuente: Elaboración propia a partir de los documentos analizados.

\section{Figura 4}

\section{ÁMBITO ESPACIAL DE LOS PROGRAMAS DE TURISMO SOSTENIBLE APROBADOS EN ANDALUCÍA EN EL PERÍODO 2007-2011*}

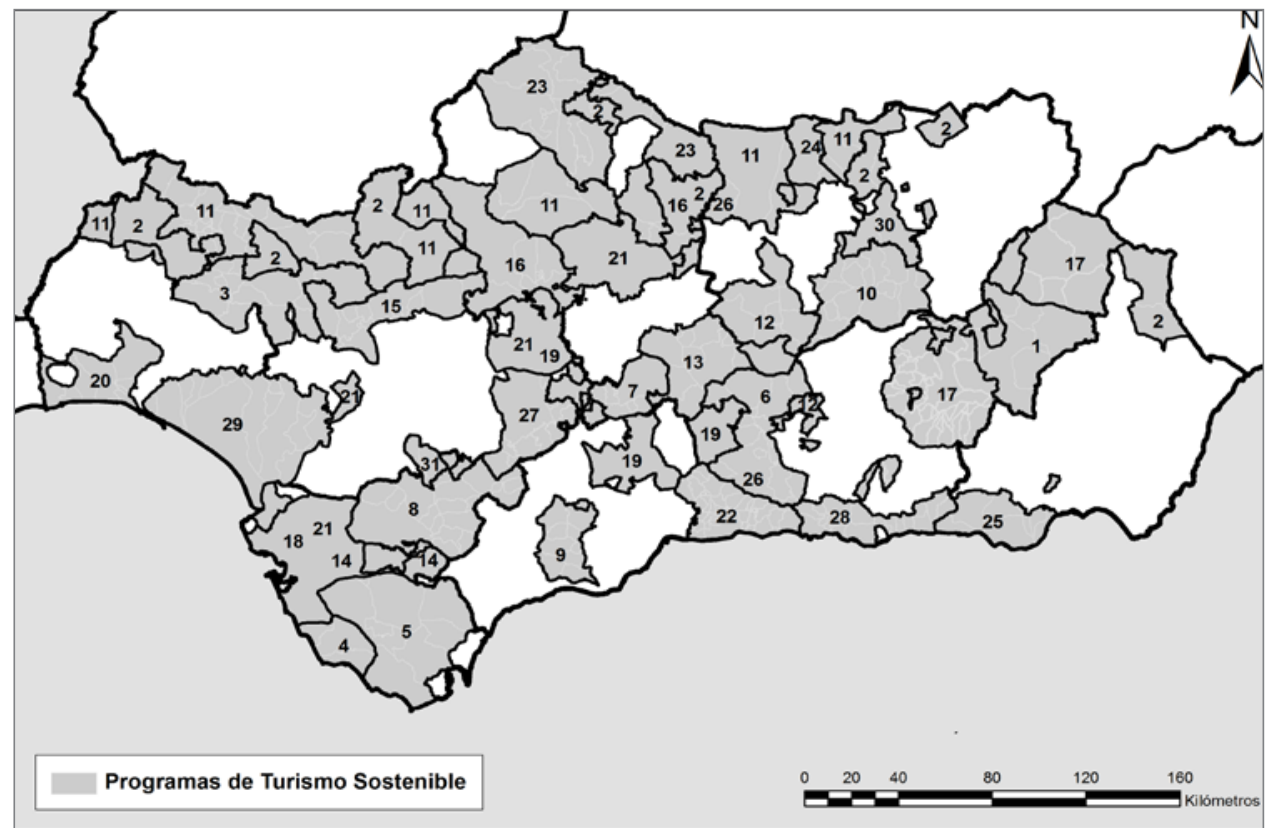

Fuente: Elaboración propia. * La numeración se corresponde con la lista de programas del Cuadro 1. 


\section{RESULTADOS DE LA INVESTIGACIÓN. EL TRATAMIENTO DEL PAISAJE EN LOS PROGRAMAS DE TURISMO SOSTENIBLE DE ANDALUCÍA}

\subsection{La consideración del paisaje en los apartados de información y diagnóstico de los documentos analizados}

El análisis pormenorizado de los 31 Programas de Turismo Sostenible que conforman el objeto de esta investigación ofrece una serie de resultados de interés sobre la consideración y el tratamiento que se realiza del paisaje en los apartados de información y diagnóstico de dichos instrumentos de planificación turística.

Lo primero que habría que destacar es que no se observa una tendencia clara, y menos aún un escenario homogéneo, en lo relativo a la consideración y el tratamiento del paisaje en los documentos analizados, sino que por el contrario se puede constatar la existencia de diferentes niveles de atención a los aspectos paisajísticos, que van desde el escaso interés y la práctica ausencia de contenidos de paisajísticos en algunos Programas, hasta la presencia de conceptualizaciones elaboradas sobre el paisaje y el análisis detallado y complejo del mismo en otros.

Figura 5

\section{NIVELES DE CONSIDERACIÓN Y TRATAMIENTO DEL PAISAJE EN LOS PROGRAMAS DE TURISMO SOSTENIBLE ANALIZADOS}

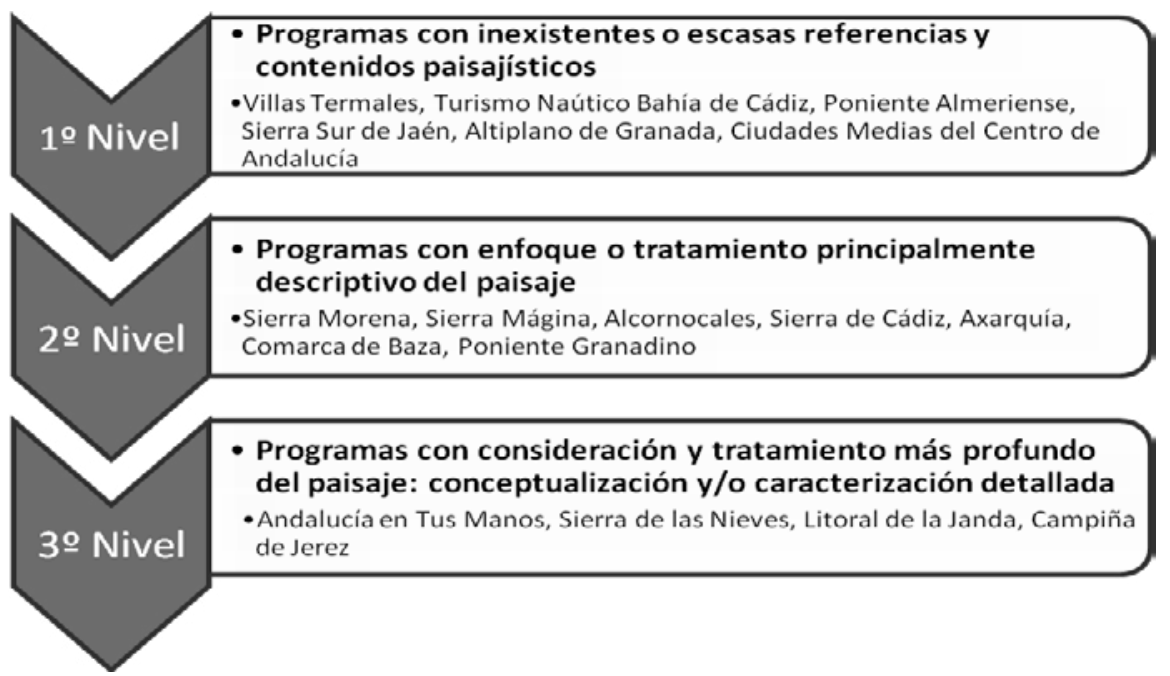

Fuente: elaboración propia.

En el sentido indicado, existe un destacable número de documentos de planificación turística (casi un tercio de los analizados) que ofrecen escasas referencias y contenidos paisajísticos. En estos documentos la conceptualización y la teorización sobre el paisaje es inexistente, mientras que el propio término paisaje aparece explícitamente en pocas 
ocasiones, cuando no se intuye de manera implícita tras descripciones muy generales y obvias del territorio. Entre estos documentos encontramos desde aquellos planes que presentan un perfil claramente sectorial turístico (caso del Programa de las Villas Termales de Andalucía o el del Turismo Náutico en la Bahía de Cádiz, en los que el paisaje brilla por su ausencia), hasta otros con una orientación nítidamente territorial pero que sorprendentemente no prestan atención al paisaje (caso de los Programas del Poniente Almeriense, el Altiplano de Granada, la Sierra Sur de Jaén o las Ciudades Medias del Centro de Andalucía).

En un segundo nivel de atención o de interés por los aspectos paisajísticos se encuentran aquellos Programas cuyos contenidos de esa naturaleza se reducen a un enfoque o tratamiento descriptivo del paisaje. La mitad de los instrumentos analizados presentan contenidos paisajísticos en un sentido fundamentalmente descriptivo, o dicho de otra forma, sus referencias paisajísticas se centran básicamente en la descripción del paisaje de la zona objeto del plan. En la mayoría de los casos se trata de descripciones un tanto convencionales y superficiales (en el sentido de atender exclusivamente al fenopaisaje), sin mucho nivel de detalle y que raramente abordan las razones causales o explicativas, no visibles, que están en el origen de esos paisajes (criptopaisaje). Este sería el caso de Programas como los de Sierra Morena, Sierra Mágina, Alcornocales, Sierra de Cádiz, Axarquía, Comarca de Baza o Poniente Granadino.

Sólo en contadas ocasiones se observa un análisis paisajístico más profundo (tercer nivel de atención observado), como en el caso del Programa de la Sierra de las Nieves y en menor medida en los del Litoral de la Janda y la Campiña de Jerez, donde el apartado referido al paisaje de la zona ha sido realizado de forma más concienzuda y superando las habituales descripciones un tanto convencionales y repetitivas. Así por ejemplo, en el primero de los documentos citados, tras dividir el territorio en 8 grandes unidades de relieve y 14 sectores, se distinguen hasta 26 unidades de paisaje y 68 subunidades, lo cual pone de manifiesto la prolijidad de la caracterización paisajística llevada a cabo.

En otros casos, como en el Programa Andalucía en Tus Manos (que abarca 17 municipios de los ámbitos funcionales de Osuna y Estepa, en el SE de la provincia de Sevilla) la descripción y el análisis del paisaje se acompaña de una conceptualización del mismo próxima a los principios de la Convención Europea del Paisaje, en el sentido de que éste se concibe como la expresión visible de la relación histórica de una sociedad con el medio sobre el que se asienta, como una manifestación significativa de la forma de gestión de los recursos naturales y culturales por parte de esa sociedad y, en definitiva, como un indicador de la calidad de vida de dicha sociedad. A todo ello se añade también la consideración del paisaje como una realidad que admite múltiples lecturas e interpretaciones dependiendo del observador y del momento, y que constituye una fuente de indudable valor para profundizar en el conocimiento y la comprensión de un territorio y su evolución histórica.

Una vez señalados los diferentes niveles de consideración y tratamiento del paisaje en los documentos de planificación turística analizados, conviene hacer referencia a los contenidos paisajísticos que aparecen más habitualmente en los mismos y que constituyen, si se permite la expresión, el «bagaje paisajístico» de buena parte de los instrumentos de planificación turística formulados en Andalucía en los últimos años. 
1) En primer lugar, y comenzando desde lo más general, en casi la mitad de los Programas analizados (12 documentos) se destaca el carácter singular, especial o incluso excepcional del propio paisaje, es decir, del paisaje o los paisajes característicos de la zona objeto del plan. La importancia de esta consideración va más allá del reconocimiento o la estima de los valores, las especificidades y el carácter del propio paisaje, para engarzar con el concepto de diferenciación tanto en el sentido territorial como en el turístico (concepto clave y omnipresente, por cierto, en el Plan General de Turismo Sostenible de Andalucía, todavía vigente).

Así, en múltiples ocasiones, a las expresiones «paisaje singular», «especial» o «excepcional», se une el término «diferente», recalcándose que el paisaje es un factor de diferenciación tanto desde el punto de vista territorial como, más específicamente, desde el punto de vista turístico. Esto se observa con mayor claridad en los Programas circunscritos a zonas mineras, caso del de la Faja Pirítica del Suroeste Peninsular o el de los Paisajes Mineros de Jaén, en los que se subraya el carácter único y peculiar de sus paisajes, lo que supone un elemento de diferenciación de estos ámbitos frente a otros espacios o destinos turísticos.

También en algunos de los Programas centrados en zonas litorales se destaca el carácter especial o excepcional del paisaje (caso del plan de Doñana, el del Litoral de la Janda o el de la Costa Tropical de Granada), señalándose que ello contribuye a su diferenciación frente a otros destinos litorales competidores y a su mejor posicionamiento en los mercados turísticos más cualificados ${ }^{3}$. Por último, los Programas localizados en zonas naturales y rurales del interior de Andalucía no se quedan atrás y en ellos también aparecen referencias a la singularidad o excepcionalidad de muchos de sus paisajes, en especial a los más valiosos y característicos desde el punto de vista natural (caso de Doñana o de los Alcornocales) o a los paisajes agrarios tradicionales que cuentan con mayor reconocimiento (caso de las dehesas, los olivares, los almendrales o los cultivos en bancales, por citar algunos ejemplos significativos).

2) Otros contenidos que guardan una estrecha relación entre sí y que aparecen de forma repetida en muchos de los documentos analizados son las referencias a los «valores paisajísticos» y a la «riqueza y la diversidad paisajísticas» de los ámbitos territoriales abordados. En 10 Programas se señala a los «valores paisajísticos» como un recurso fundamental del territorio y como un elemento clave de atracción del mismo, mientras que «la riqueza y la diversidad paisajísticas» son concebidas o como un valor esencial del territorio o como un factor clave para su revalorización en al menos 8 documentos.

Ligada a estas consideraciones estaría la concepción del paisaje o del «patrimonio paisajístico» como un factor de desarrollo o de dinamización socioeconómica, pudiéndose constituir el paisaje en un auténtico «motor» para la puesta en marcha de nuevas actividades, entre ellas las vinculadas a los aprovechamientos turísticos y recreativos (plantea-

3 Así, en el plan del Litoral de la Janda se afirma que las características paisajísticas de este sector de la costa gaditana permiten su diferenciación frente a otros tramos de costa cada vez más estandarizados y trivializados desde el punto de vista paisajístico y arquitectónico. Por su parte, en el plan de la Costa Tropical de Granada se señalan sus especiales características paisajísticas y climáticas como elementos de diferenciación que le permiten un mejor posicionamiento como destino turístico de cara al futuro. 


\section{Figura 6 \\ PRINCIPALES CONTENIDOS PAISAJÍSTICOS DE LOS DOCUMENTOS ANALIZADOS}

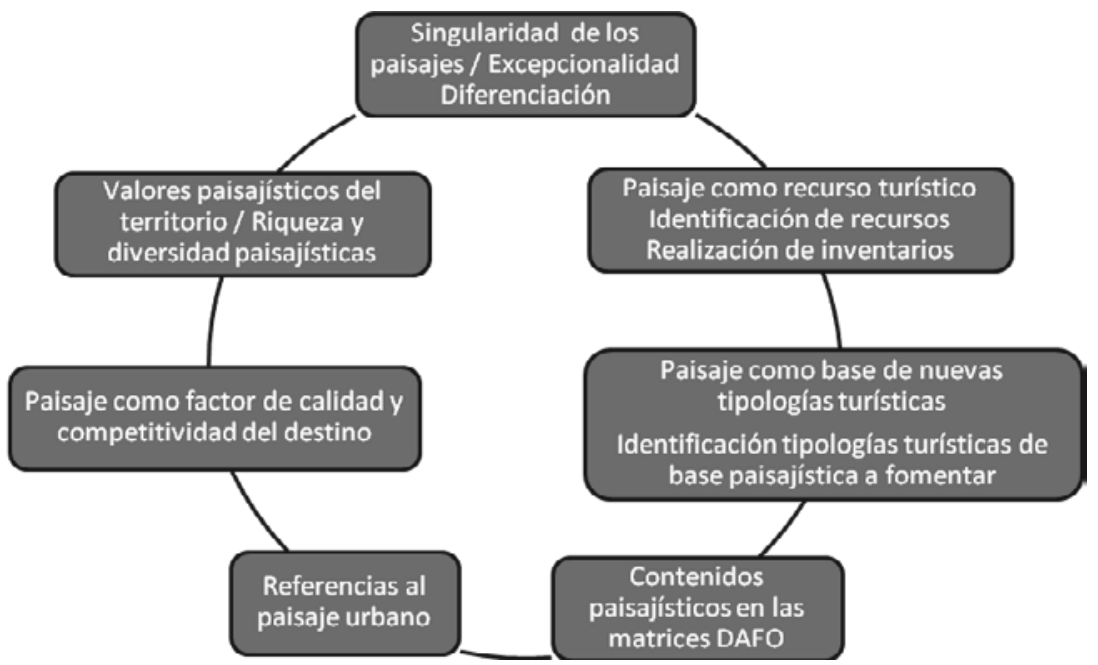

Fuente: elaboración propia.

miento que aparece expresado de forma clara en los Programas del Valle del Guadalquivir, Vía Verde de la Sierra, Andalucía en Tus Manos y Conjuntos Históricos de Andalucía).

3) Profundizando en la última cuestión señalada, algo común a la mayoría de los Programas (18 documentos) es la consideración del paisaje como un recurso turístico y como la base de determinadas tipologías turísticas que están presentes o que pueden desarrollarse en el territorio en cuestión.

En este sentido, en un buen número de planes la concepción del paisaje como recurso turístico alcanza cotas muy elevadas, al ser considerado como uno de los principales valores del territorio de cara a su desarrollo turístico, cuando no el más importante. Así, en el documento de la Faja Pirítica del Suroeste Peninsular se habla de un «desarrollo turístico basado en gran medida en el paisaje, en lo característico de sus paisajes», mientras que en el Programa de Sierra Mágina se señala al paisaje como «uno de los principales valores de la comarca y un recurso clave para el desarrollo del turismo rural». También en el Programa de Doñana se considera al paisaje como una «seña de identidad del territorio muy importante para el desarrollo turístico», mientras que en otros documentos como el del Litoral de la Janda, el de la Comarca de Baza, el de Sierra Morena o el de la Ruta del Tempranillo, se incide repetidamente sobre el argumento general que sitúa al paisaje como uno de los principales recursos para el desarrollo turístico.

Esos planteamientos se concretan en un buen número de Programas (15 documentos) en la identificación de recursos o el establecimiento de inventarios (en su mayoría de equipamientos de uso público) que permitan el disfrute y/o la interpretación del paisaje: caso de los miradores para la observación y la «lectura» del paisaje, o caso de los senderos, 
las vías verdes y otro tipo de caminos como base para la creación de rutas, por señalar los elementos con mayor presencia en los documentos analizados. Sirvan de ejemplo de este ejercicio de inventariación los Programas de la Subbética Cordobesa, Sierra de las Nieves, Axarquía o Costa Occidental de Huelva, entre otros muchos.

4) Por otra parte, no debe olvidarse la referencia expresa que aparece en muchos Programas (al menos en 9) a la necesidad de fomentar tipologías turísticas concretas que tienen su base de forma más o menos directa en los valores paisajísticos del territorio, caso del turismo de naturaleza, el turismo rural, el turismo minero o el turismo activo (senderismo, cicloturismo, turismo ecuestre, etc.). En definitiva, lo que se quiere transmitir es que el paisaje es elemento imprescindible para el diseño de nuevos productos turísticos, algunos de ellos todavía no implantados en muchos de los ámbitos analizados y para los que el paisaje se erige en el principal factor de generación de los mismos.

5) Otro aspecto que merece especial atención y que aparece de forma expresa en algunos documentos (caso de los Programas del Valle del Guadalquivir, la Ruta del Tempranillo o Andalucía en Tus Manos) es la concepción del paisaje como un factor de calidad del destino turístico y que incide claramente sobre la competitividad del mismo. Con ello se da un paso más en la consideración del paisaje en relación con la actividad turística, al atribuirle un papel clave en la experiencia turística y en la satisfacción de los visitantes. En el Programa Andalucía en Tus manos se expresa de forma muy elocuente, al señalarse que la autenticidad y la armonía del paisaje determinan en gran medida la calidad de la experiencia turística de los visitantes ${ }^{4}$.

En este sentido, en muchos documentos se señala que el paisaje constituye una importante motivación para los visitantes, tanto turistas como excursionistas, llegando en algunos casos a ser la motivación más relevante para la elección del destino (Sierra Mágina, Sierra de Cádiz, Faja Pirítica, Sierra de las Nieves o Via Verde de la Sierra). Esta afirmación suele acompañarse de datos estadísticos y otro tipo de valoraciones derivadas de la realización de encuestas a visitantes, en las que el paisaje aparece como uno de los elementos más apreciados del destino (así por ejemplo, en la Sierra de las Nieves o en el ámbito de la Faja Pirítica la valoración del paisaje por parte de los visitantes es de 9 sobre 10, la más alta de entre los diversos componentes del destino considerados en la encuesta).

6) Hasta el momento, el grueso de las referencias y los contenidos paisajísticos a los que se ha hecho alusión en este epígrafe están relacionados con los paisajes de dominante natural, rural o minero, mayoritarios en los ámbitos abordados por los documentos analizados. Pero esto no significa que no existan referencias a otro tipo de paisajes, como por ejemplo los urbanos, aunque aparezcan de una forma menos generalizada.

En este sentido, las referencias al paisaje urbano se centran principalmente en la necesidad de respetar y proteger los valores paisajísticos de los hitos y los conjuntos monumen-

4 Esta idea conecta con el planteamiento observado en otros Programas (Litoral de la Janda o Campiña de Jerez) que insiste en la necesidad de prestar gran atención al paisaje en la medida en que éste constituye el escenario o telón de fondo sobre el que se desarrolla cualquier actividad turística, erigiéndose por tanto en un factor esencial para la satisfacción global del visitante. Este planteamiento se combina y se completa con el ya expresado de la consideración del paisaje como recurso y como materia prima para el desarrollo de actividades y productos turísticos. 
tales, además de los de la arquitectura y el urbanismo tradicionales, frente a los impactos que pudieran producir las nuevas actuaciones y desarrollos urbanísticos (Programas de Ubeda y Baeza, Sierra de Cádiz o Sierra Sur de Jaén).

Otras observaciones sobre el paisaje urbano con una presencia menor sugieren la necesidad de extender el tratamiento paisajístico al entorno de los elementos monumentales, de forma que prime la actuación sobre el contexto o el conjunto frente al tratamiento paisajístico puntual (Programa Andalucía en Tus Manos); o la necesidad de realizar actuaciones urbanísticas sobre los bordes urbanos y los accesos a los núcleos, al ser considerados éstos como una importante carta de presentación de los municipios ante los visitantes (idem).

Con una presencia anecdótica, sólo observada en el caso de Doñana, habría que señalar la referencia a la oportunidad de abordar la rehabilitación urbana y la recualificación de los núcleos turísticos maduros mediante actuaciones de carácter paisajístico entre otras (medida que se plantea para los núcleos de Matalascañas y Mazagón, ubicados en el sector occidental de la primera línea de costa de este ámbito).

7) Finalmente, los aspectos o contenidos paisajísticos tienen una presencia importante en las matrices DAFO que aportan todos los documentos analizados en su correspondiente apartado del diagnóstico territorial y turístico ${ }^{5}$.

En el ámbito de las debilidades, la mayoría de los contenidos de carácter paisajístico hacen referencia al deficiente estado de conservación de determinados elementos o recursos de interés paisajístico (senderos, puntos de observación, edificios singulares, etc.), así como a la pérdida de personalidad e identidad de algunos paisajes tradicionales y valiosos desde el punto de vista patrimonial (tanto urbanos como rurales), o también a los problemas observados en materia de señalización (falta de homogeneidad, escasa integración paisajística de la misma, etc.).

Por lo que respecta a las amenazas, destaca por encima de todo la preocupación por los impactos paisajísticos que puedan generar las nuevas actuaciones urbanísticas, las infraestructuras de todo tipo y determinadas actividades productivas. En este sentido, se advierte de los riesgos de degradación paisajística que pueden conllevar tanto los nuevos desarrollos urbanísticos como las actuaciones sobre la trama urbana preexistente; así como la implantación de infraestructuras como los aerogeneradores, los vertederos o el cableado en los ámbitos urbanos; además de la localización de actividades productivas de elevado impacto paisajístico como la extracción de áridos (canteras) o la agricultura intensiva bajo plásticos (invernaderos).

En lo relativo a las fortalezas, la mayoría de los contenidos observados hacen referencia a la riqueza y el atractivo paisajístico de las zonas objeto de planificación, a su diversidad paisajística, y a menudo también a la existencia de vías o caminos con valores paisajísticos y puntos de observación que ofrecen vistas panorámicas.

5 Ha de señalarse que la matriz DAFO constituye uno de los contenidos que han de contemplar necesariamente las propuestas de planificación turística que se formulen y se presenten para optar a las ayudas derivadas de la ejecución de la Estrategia de Turismo Sostenible de Andalucía, según se desprende de la guía metodológica diseñada al efecto por la administración turística regional para los agentes interesados. 
Por último, en el apartado de oportunidades se destaca la posibilidad de poner en valor muchos elementos o recursos naturales y culturales que pueden servir para conocer, disfrutar e interpretar el paisaje (caminos como base para la realización de rutas, torres desde las que observar el paisaje, edificios para localización de centros de interpretación, etc.). A ello se unen las referencias a las potencialidades de muchos ámbitos para el desarrollo de nuevas actividades y productos turísticos encuadrables en tipologías o modalidades turísticas directamente vinculadas a los valores paisajísticos del territorio (senderismo, cicloturismo, turismo ecuestre, agroturismo, diversas actividades de turismo de naturaleza como el turismo ornitológico o la caza fotográfica, etc.).

\subsection{La atención al paisaje en el apartado propositivo de los documentos: la dedica- ción financiera a acciones vinculadas al paisaje}

Tras analizar la consideración y el tratamiento que se hace del paisaje en los apartados de información y diagnóstico de los Programas, procede ahora evaluar la atención y la dedicación real prestada a los aspectos paisajísticos en dichos Programas, lo cual se deducirá de las propuestas concretas que se formulen en los documentos y, sobre todo, de la asignación financiera a los distintos tipos de acción y sus proyectos asociados.

Para ello, se va a tomar como punto de partida el peso económico que tiene el conjunto de acciones y proyectos relacionados directamente con el paisaje en los distintos Programas (cuadro 2), para continuar después con el análisis pormenorizado de los diversos tipos de acción de carácter paisajístico a las que se dedican recursos financieros por parte de los planes (figura 7).

De los datos que se exponen en el cuadro 2 se extrae, como primera evidencia, que una elevada proporción de Programas dedica una importante asignación financiera a acciones y proyectos relacionados directamente con el paisaje, tal y como se deduce del hecho de que 18 documentos (casi el 60\% de los mismos) destine más del $20 \%$ de su presupuesto a este tipo de acciones (por encima del 17,6\% de media empleado por el conjunto total de los planes).

En muchos de esos casos se pone de relieve que la dedicación financiera a acciones y proyectos paisajísticos es mayor que la consideración y el tratamiento otorgado al paisaje en los apartados de información y diagnóstico, como puede comprobarse en los Programas de la Sierra de Cádiz, Altiplano de Granada, Sierra Morena, Poniente Almeriense, Poniente Granadino, Conjuntos Históricos de Andalucía, Comarca de Baza o Alcornocales. La posible causa de este desajuste entre el tratamiento teórico y analítico del paisaje en los documentos (escaso) y el nivel de la asignación financiera a las propuestas de carácter paisajístico (elevado) será expuesta en las conclusiones del artículo.

En el extremo opuesto al que acaba de señalarse estarían los Programas que a pesar de contar con una conceptualización rica en relación con el paisaje, con una caracterización detallada del mismo o con un reconocimiento de sus valores singulares, dedican escasos recursos financieros a acciones paisajísticas, caso de los Programas Andalucía en Tus Manos, Doñana o Paisajes Mineros de Jaén. En estos casos resulta evidente que, a pesar del discurso existente en los documentos, el compromiso real con el paisaje es bastante escaso (con asignaciones financieras del $1 \%$, el $2,5 \%$ y el $12 \%$ del total del presupuesto respectivamente). 


\section{Cuadro 2}

SIGNIFICACIÓN ECONÓMICA DE LAS ACCIONES Y PROYECTOS RELACIONADOS DIRECTAMENTE CON EL PAISAJE EN LOS PROGRAMAS

\begin{tabular}{|c|c|c|c|}
\hline Programa & $\begin{array}{l}\text { Presupuesto total del } \\
\text { Programa (euros) }\end{array}$ & $\begin{array}{l}\text { Presupuesto dedicado } \\
\text { a acciones y proyectos } \\
\text { paisajísticos (euros) }\end{array}$ & $\begin{array}{c}\% \text { sobre el } \\
\text { presupuesto total }\end{array}$ \\
\hline Vía Verde de la Sierra & 2.450 .000 & 1.800 .000 & 73,47 \\
\hline Sierra de Cádiz & 7.707 .000 & 4.045 .717 & 52,49 \\
\hline $\begin{array}{l}\text { Altiplano Granada. Pais. } \\
\text { Troglod. }\end{array}$ & 23.158 .000 & 11.692 .820 & 50,49 \\
\hline Sierra Morena & 17.323 .000 & 7.431 .501 & 42,90 \\
\hline Poniente Almeriense & 42.377 .000 & 16.991 .972 & 40,10 \\
\hline Poniente Granadino & 9.632 .000 & 3.597 .000 & 37,34 \\
\hline Conjuntos Históricos Andalucía & 14.516 .000 & 5.041 .000 & 34,73 \\
\hline Comarca de Baza & 10.793 .000 & 2.987 .340 & 27,68 \\
\hline Los Alcornocales & 16.620 .000 & 4.333 .334 & 26,07 \\
\hline Vega del Guadalquivir & 35.000 .000 & 8.625 .115 & 24,64 \\
\hline Subbética Cordobesa & 23.800 .000 & 5.836 .267 & 24,52 \\
\hline Costa Occidental de Huelva & 16.032 .000 & 3.872 .000 & 24,15 \\
\hline Sierra de las Nieves & 8.125 .000 & 1.925 .000 & 23,69 \\
\hline Litoral de la Janda & 15.925 .000 & 3.650 .000 & 22,92 \\
\hline Úbeda y Baeza & 56.258 .000 & 11.813 .000 & 21,00 \\
\hline Campiña de Jerez & 10.021 .000 & 2.100 .000 & 20,96 \\
\hline Ruta del Tempranillo & 12.000 .000 & 2.450 .000 & 20,42 \\
\hline Sierra Mágina & 11.330 .000 & 2.298 .000 & 20,28 \\
\hline La Axarquía & 168.807 .000 & 33.535 .438 & 19,87 \\
\hline Ciudades Medias Centro Andal. & 24.450 .000 & 3.955 .000 & 16,18 \\
\hline Faja Pirítica Suroeste Penins. & 42.000 .000 & 6.486 .476 & 15,44 \\
\hline Valle del Guadalquivir & 14.171 .000 & 1.795 .273 & 12,67 \\
\hline Doñana & 21.961 .000 & 2.672 .000 & 12,17 \\
\hline Sierra Sur de Jaén & 4.900 .000 & 448.000 & 9,14 \\
\hline Costa Tropical Granada & 120.100 .000 & 10.856 .000 & 9,04 \\
\hline Los Pedroches & 18.023 .000 & 1.061 .021 & 5,89 \\
\hline Paisajes Mineros de Jaén & 5.000 .000 & 125.000 & 2,50 \\
\hline Andalucía en Tus Manos & 11.417 .427 & 113.000 & 0,99 \\
\hline Villas Termales Andalucía & 128.530 .000 & 300.000 & 0,23 \\
\hline Guadalquivir a Caballo & 16.877 .000 & 0 & 0,00 \\
\hline Turismo Náutico Bahía Cádiz & 10.500 .000 & 0 & 0,00 \\
\hline Total & 919.803 .427 & 161.837 .274 & 17,59 \\
\hline
\end{tabular}

Fuente: elaboración propia a partir de los Programas analizados. 
Por último, en una situación intermedia, se encontrarían los Programas en los que la dedicación financiera a acciones paisajísticas resulta acorde con el tratamiento que se hace del paisaje en los capítulos de información y diagnóstico del documento. Tal es el caso de los Programas de la Sierra de las Nieves, Litoral de la Janda, Úbeda y Baeza y Campiña de Jerez, en los que el tratamiento teórico del paisaje adopta un enfoque que combina la descripción y el reconocimiento de los principales valores paisajísticos del ámbito (nivel medio de consideración, véase figura 5), mientras que la dedicación financiera a acciones directamente relacionadas con el paisaje se sitúa entre el 20 y el $25 \%$ del total del presupuesto del Programa (nivel medio de inversión, véase cuadro 2).

En lo relativo al análisis pormenorizado de los distintos tipos de acción vinculadas al paisaje a las que se dedican recursos financieros por parte de los Programas (figura 7), se pueden extraer las siguientes consideraciones:

1) En primer lugar se observa cómo la acción y los proyectos de índole paisajístico a los que se dedican mayores recursos financieros en los Programas son los que se orientan al «embellecimiento de los entornos y los accesos a los recursos de interés turístico» (acción c.1. según la normativa reguladora de la Estrategia de Turismo Sostenible de Andalucía, que es la que determina los tipos de acciones subvencionables para los Programas analizados). Dicho capítulo acapara más del 50\% del montante económico dedicado a acciones paisajísticas y casi un $10 \%$ del presupuesto total del conjunto de los Programas.

El epígrafe señalado incluye actuaciones y proyectos diversos que van desde el acondicionamiento y la mejora de las vías de acceso e interiores de los núcleos, hasta la recuperación de elementos propios de la arquitectura y el urbanismo tradicional, pasando por la iluminación de edificios y entornos urbanos, la eliminación de cableado o el soterramiento de contenedores.

En todo caso se trata de una línea de actuación con una fuerte tradición en nuestro entorno, generalmente poco innovadora en cuanto a sus contenidos, y que denota fundamentalmente un interés por los valores estéticos y el aspecto externo del paisaje urbano, en cuanto que escenario en el que se desarrollan parte importante de las actividades turísticas y que determina en gran medida la satisfacción de los visitantes.

Entre los Programas que dedican mayores recursos financieros a este tipo de acciones destacan los que actúan de forma significativa sobre conjuntos urbanos o sobre núcleos rurales de elevado valor patrimonial (caso de los Programas de Úbeda y Baeza, Conjuntos Históricos de Andalucía, Ciudades Medias de Andalucía, Axarquía o Sierra de Cádiz, por citar algunos ejemplos destacables).

2) En segundo lugar, por orden de importancia financiera, habría que hacer referencia al capítulo dedicado a la «implantación de rutas turísticas» (acción a.3. según la normativa antes referida), con un montante global superior a los 25 millones de euros (el 16\% del presupuesto destinado a acciones directamente relacionadas con el paisaje).

Se trata de un tipo de acción dirigida a la creación de productos turísticos consistentes en itinerarios que se articulan en torno a recursos de interés natural, histórico, cultural o de otro tipo, y que en general conllevan la lectura o interpretación del paisaje en el que se insertan, ya sea éste de carácter natural, rural o urbano.

Casi todos los Programas dedican recursos financieros al diseño, implantación y puesta en valor de rutas turísticas, aunque hay dos que sobresalen, Sierra Morena y Costa Tropical 


\section{Figura 7}

\section{TIPOS DE ACCIONES VINCULADAS AL PAISAJE A LAS QUE SE DEDICAN RECURSOS FINANCIEROS* EN LOS PTS}

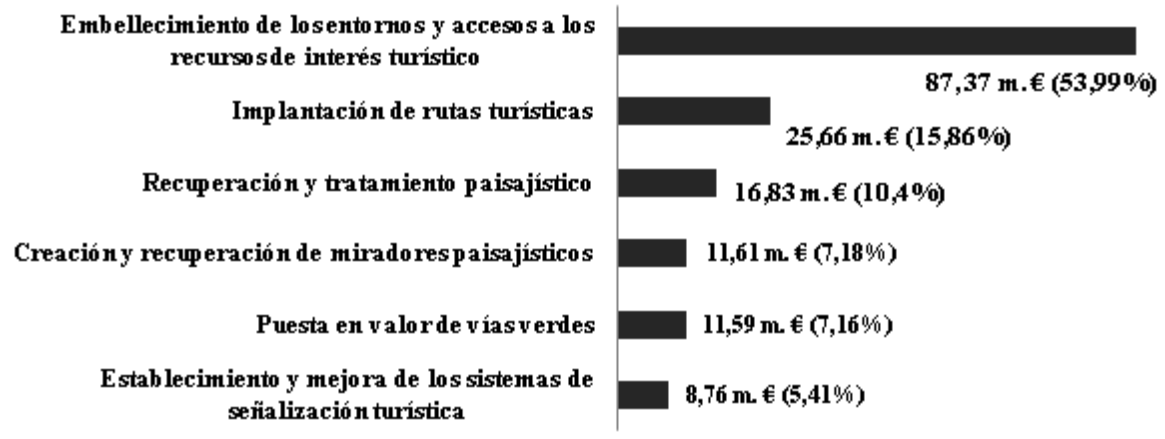

Fuente: elaboración propia a partir de los Programas de Turismo Sostenible analizados.*En millones de euros y en $\%$ con respecto al total de recursos financieros dedicados a acciones paisajísticas.

de Granada, que le dedican más de 3 millones de euros cada uno, el doble de los Programas que les siguen en términos de atención financiera a dicha acción. Otros documentos que destacan por los recursos económicos dedicados a la creación de rutas turísticas son los del Poniente Granadino, la Faja Pirítica del Suroeste Peninsular, los Paisajes Troglodíticos del Altiplano de Granada, la Costa Occidental de Huelva, la Subbética Cordobesa o Doñana.

Como puede observarse, no existe un patrón territorial claro en cuanto al tipo de Programas que dedican mayores recursos financieros a este tipo de acción, ya que entre los 10 más relevantes encontramos desde planes cuyo ámbito de actuación son espacios naturales, hasta otros que se circunscriben a ámbitos litorales, zonas rurales e incluso espacios mineros. También los proyectos concretos propuestos son muy variados y se plantea la creación de rutas turísticas de muy diverso tipo: naturalísticas, forestales, geológicas, de interpretación de la costa, arqueológicas, históricas, artísticas, arquitectónicas, etnológicas, en torno a personajes ilustres, culinarias, comerciales, etc.

3) El tercer tipo de acción relacionada directamente con el paisaje a la que se dedican mayores recursos financieros en el apartado propositivo de los Programas es la denominada «recuperación y tratamiento paisajístico» (acción c.5), una de las dos que incluye expresamente en su título el término paisaje. En total se destina a ello casi 17 millones de euros, más del $10 \%$ del total dedicado a acciones paisajísticas en los planes.

Se trata de la acción que presenta una delimitación menos precisa de las 6 relacionadas directamente con el paisaje (véase figura 7), ya que bajo el título señalado cabe un sinfín de actuaciones muy diversas, en definitiva cualquier proyecto de carácter paisajístico que no encaje o que no esté contemplado en el resto de acciones, las cuales están más claramente definidas en cuanto a sus contenidos.

Del análisis de los Programas se deduce un panorama muy heterogéneo en cuanto a los tipos de proyectos propuestos en el marco de esta acción, contemplándose actuaciones muy variadas dirigidas a la creación o la mejora de áreas recreativas y de ocio, parques periur- 
banos, anillos y corredores verdes, jardines y parques urbanos, paseos marítimos, paseos fluviales, áreas degradadas en el entorno de espacios naturales o núcleos urbanos, etc.

Entre los Programas que dedican mayores recursos financieros a este tipo de acción destacan los circunscritos a ámbitos naturales y rurales, caso de los Programas de la Axarquía, Vega del Guadalquivir, Subbética Cordobesa, Sierra Mágina, Altiplano de Granada, Alcornocales o Campiña de Jerez. Sólo dos Programas de otro tipo, el de la Costa Tropical de Granada y el del Litoral de la Janda, ambos de ámbitos litorales, aparecen entre los 10 que dedican mayor presupuesto a esta acción de recuperación y tratamiento paisajístico.

4) Otro tipo de acción a la que se dedica una cuota importante de los recursos financieros destinados a actuaciones vinculadas al paisaje es la orientada a la «creación y recuperación de miradores paisajísticos» (acción c.4), con un volumen de inversión global cercano a los 12 millones de euros (el 7,2\% del presupuesto total dedicado a acciones paisajísticas).

El objetivo de esta línea de actuación está claramente definido en su propia denominación y se dirige tanto a la creación de nuevos miradores paisajísticos, como a la recuperación, adecuación y mejora de los ya existentes. La mayoría de los Programas analizados contempla alguna propuesta de este tipo, aunque los más destacables en virtud de los recursos financieros asignados tienen como ámbito de actuación espacios naturales de carácter serrano, caso de la Axarquía, Sierra Morena, la Subbética Cordobesa o los Alcornocales, cada uno de ellos con un presupuesto para miradores paisajísticos superior al millón de euros.

Sirva de ejemplo de este tipo de proyectos la denominada «Ruta interpretativa de miradores de Sierra Morena», articulada en torno a un mínimo de 12 miradores en toda la sierra y que conlleva la realización de un inventario de posibles emplazamientos, la evaluación de su situación actual, el análisis de sus potencialidades turísticas, la definición de sus posibles contenidos y finalmente, una vez seleccionados los lugares más idóneos, el acondicionamiento, la señalización y la instalación de paneles interpretativos para facilitar la comprensión de los paisajes observados (en total una inversión prevista de más de 1,4 millones de euros en dicho proyecto).

5) La acción denominada «puesta en valor de vías verdes» (acción a.5) es otra de las que tiene unas implicaciones paisajísticas más claras, ya que supone la recuperación y el acondicionamiento de los antiguos trazados de ferrocarril (y de otro tipo de caminos) de cara a su reaprovechamiento a través de usos deportivos, recreativos, didácticos y turísticos. En total se dedican 11,6 millones de euros a esta acción en los documentos analizados, el 7,2\% del presupuesto empleado en acciones paisajísticas.

Los proyectos de mayor envergadura económica de puesta en valor de Vías Verdes se localizan en ámbitos donde se plantea la creación de nuevas vías (caso del tramo comprendido entre Vélez Málaga y las Ventas de Zafarraya, en la Axarquía malagueña), lo cual supone la realización de numerosas y costosas actuaciones: realización de estudios técnicos, obras de reparación y acondicionamiento, construcción de áreas recreativas, rehabilitación de edificios para diferentes usos y recuperación de sus entornos, señalización, elaboración de material informativo, acciones de promoción, etc. (en total una inversión prevista para dicho proyecto cercana a los 6 millones de euros).

Otros proyectos relevantes son los relacionados con la mejora de las Vías Verdes existentes, caso de la Vía Verde de la Sierra (1,8 millones de euros) o la Vía Verde Litoral de la 
costa occidental de Huelva (1,4 millones de euros). En ambos casos las actuaciones se dirigen a la mejora del trazado de la vía, la rehabilitación de edificios para dotarlos de nuevos usos, la mejora y adecuación de las áreas de descanso y de los puntos de información, etc.

6) Finalmente, el último tipo de acción destacable en virtud de su importancia financiera es la que se orienta al «establecimiento y mejora del sistema de señalización turística» (acción c.2), a la que se dedican 8,8 millones de euros, el 5,4 del total de presupuesto destinado a acciones relacionadas con el paisaje. Casi todos los Programas dedican recursos económicos a este capítulo, al observarse problemas comunes en la mayoría de los ámbitos objeto de planificación como la señalización inexistente o insuficiente, la falta de homogeneidad en términos de diseño, la existencia de una señalización que induce a confusión, el impacto visual de la misma, etc.

Así pues, Programas referidos a ámbitos de distinto tipo (urbanos, litorales, rurales y naturales) prestan por igual atención al tema de la señalización turística, aunque a modo de ejemplo puedan destacarse los proyectos contenidos en el Programa de Úbeda y Baeza, debido a su nivel de detalle. En este documento se distingue entre proyectos de «señalización turística direccional», proyectos de «señalización turística interpretativa» y proyectos de «señalización monumental turística peatonal», que se diferencian en función de los objetivos perseguidos por cada tipo de señalización, el tipo y el nivel de detalle de la información que han de proporcionar al visitante y las características técnicas de los soportes a emplear ${ }^{6}$.

\section{CONCLUSIONES}

Las principales conclusiones obtenidas en el curso de la investigación realizada han sido las siguientes:

- La estrecha y al mismo tiempo conflictiva relación existente entre turismo y paisaje, en la que éste aparece como recurso de primera magnitud para el desarrollo de la actividad turística, al mismo tiempo que factor esencial para la competitividad de los destinos turísticos ante las nuevas tendencias de la demanda.

- Pese a lo anterior, se observa una generalización de impactos negativos de las actividades e instalaciones turísticas sobre el paisaje; así como una muy escasa tradición de tratamiento de la temática paisajística en la planificación de destinos, ya sea para rentabilizar sus potencialidades como recurso o ya sea para prevenir o reducir los impactos.

- En los últimos años, sin embargo, y muy especialmente a partir de la aplicación de los compromisos que la Convención Europea del Paisaje establece para sus Esta-

6 Los proyectos de «señalización turística direccional» tienen como objetivo orientar a los visitantes a su llegada a los núcleos urbanos e informar sobre la localización de las principales infraestructuras turísticas; los proyectos de «señalización turística interpretativa» pretenden facilitar al visitante la interpretación de los principales atractivos turísticos de Úbeda y Baeza, mediante información facilitada en tres idiomas en monolitos ubicados junto a dichos atractivos; finalmente, los proyectos de «señalización monumental turística peatonal» tienen como objetivo identificar los recursos turísticos incluidos en los itinerarios peatonales existentes, mediante una placa cerámica ubicada en el suelo junto a dichos recursos. 
dos firmantes (España la ratificó oficialmente en 2008), se asiste a una creciente incorporación del paisaje como objeto de atención por parte de las administraciones públicas; tendencia a la que de forma pausada pero progresiva se va sumando la planificación turística.

- La política turística de la Administración Autonómica Andaluza, con los claroscuros derivados de la crisis presupuestaria atravesada, ha incorporado desde finales de la década pasada el paisaje en sus documentos de planificación; habiéndose puesto de relieve en el texto los precedentes más significativos, culminados en la experiencia de la Estrategia de Turismo Sostenible de Andalucía, sobre la que se centra la investigación.

- Desde el punto de vista metodológico, se constata que, pese a las dificultades inherentes a la escasa concreción con la que el concepto de paisaje es aún utilizado en el lenguaje administrativo, con una metodología como la aquí planteada es posible llegar a conclusiones ciertas acerca de cómo es incorporado el paisaje en las distintas fases de la planificación turística: intensidad de tratamiento, enfoques empleados, contenidos temáticos preferentes, entidad de los recursos financieros dedicados, y tipología de las acciones concretas propuestas.

- Así, en lo que respecta al tratamiento del paisaje en los apartados de información y diagnóstico de los documentos analizados, se observa cómo existen tres tipos de planes en función del nivel de consideración del paisaje: los que prestan una escasa atención al paisaje o que incluso no lo contemplan en sus contenidos (un grupo significativo de los Programas); los que tienen un enfoque principalmente descriptivo del paisaje (la mayoría); y los que incorporan una conceptualización y/o una caracterización detallada del paisaje (una minoría). Este panorama dispar apunta a la inexistencia de una asunción generalizada de los postulados de las políticas de paisaje por parte de los agentes promotores de los planes analizados.

- No obstante, también se observa la existencia de unos contenidos paisajísticos preferentes o que aparecen de forma habitual en muchos de los documentos, cuales son: la identificación de los principales valores paisajísticos del territorio; el reconocimiento del carácter singular o diferencial de determinados paisajes; la concepción del paisaje como recurso turístico y la consecuente realización de inventarios de recursos turístico-paisajisticos y la identificación de tipologías turísticas a fomentar; la consideración del paisaje como factor de calidad y competitividad del destino; y la existencia habitual de referencias específicas al paisaje urbano.

- En lo relativo a los contenidos propositivos de los documentos, se extrae como primera conclusión que buena parte de los Programas dedica una elevada proporción de su presupuesto a acciones y proyectos vinculados con el paisaje (más del $20 \%$ del presupuesto en el caso de 18 planes), lo cual en muchos casos está por encima de la consideración otorgada al paisaje en sus apartados de información y diagnóstico.

Esto puede deberse a la existencia de una atención no consciente o no reflexionada sobre el paisaje, es decir, no basada en elaboraciones teóricas ni en la asunción de políticas recientes como la de paisaje, sino que se explicaría por la inercia derivada de la aplicación de políticas de larga tradición y muy consolidadas, como por ejem- 
plo la de «embellecimiento» urbano (que históricamente ha incluido actuaciones de rehabilitación, adecentamiento, reequipamiento, iluminación, etc., con una clara incidencia paisajística).

- Como muestra de lo que acaba de señalarse, y en lo que se refiere a las acciones concretas vinculadas al paisaje a las que se dedican mayores recursos financieros en los planes, destaca por encima de todas la orientada al «embellecimiento de entornos y accesos a los recursos de interés turístico» (con más del 50\% del presupuesto dedicado a acciones de carácter paisajístico), seguida de la «implantación de rutas turísticas», «la recuperación y el tratamiento paisajístico», «la creación y recuperación de miradores paisajísticos», «la puesta en valor de Vías Verdes» y, finalmente, la acción dedicada al «establecimiento o mejora de la señalización turística».

Todas ellas acciones preestablecidas por la administración regional y consideradas como subvencionables en el marco de la Estrategia de Turismo Sostenible de Andalucía, lo cual limita las posibilidades de evaluar hasta qué punto existe o no una intencionalidad en tratar el paisaje y el grado de dicha intencionalidad por parte de los promotores y los equipos redactores de los Programas.

- Por último, y como conclusión de cara al futuro, parece innegable que la incorporación del paisaje en la planificación turística es una tendencia irreversible a mediolargo plazo, y ello no sólo por el desarrollo legislativo al que se han comprometido los Estados europeos, sino por la propia necesidad intrínseca del sector turístico, que no puede ignorar la trascendencia de la calidad paisajística como factor de competitividad de los destinos en un escenario de creciente competencia entre los mismos. Esta realidad abre una ventana de oportunidad a la utilización del turismo, en tanto que demostrado sector generador de rentas y empleos, como gran soporte argumental, junto a los propios valores patrimoniales, estéticos e identitarios del paisaje, para la adopción de políticas públicas que promuevan la conservación y mejora de la calidad paisajística de los territorios.

\section{BIBLIOGRAFÍA}

ACEVEDO RODRÍGUEZ, P. y DEL RISCO YERA, Y. (2000): «Fundamentos teóricometodológicos para la planificación ambiental del turismo en paisajes sensibles», Geographicalia, $\mathrm{n}^{\circ} 1$ (Extra), pp. 25-35.

ALEDO TUR, A. (2008): «De la tierra al suelo: la transformación del paisaje y el nuevo turismo residencial», Arbor: ciencia, pensamiento y cultura, nº 729, pp. 99-113.

ANTÓN CLAVÉ, S. (2010): «Identity and tourism. Between image and perception», Paradigmes, $\mathrm{n}^{\circ}$ 5, pp. 156-165.

BARDÓN FERNÁNDEZ, E. (1991): «El paisaje en la oferta turística y recreativa», Estudios Turísticos, $\mathrm{n}^{\circ} 112$, pp. 27-54.

CAMPOS CÁNOVAS, A. y LÓPEZ SÁNCHEZ, M. (2006): «Análisis, tratamiento y problemática del paisaje en los conjuntos históricos: el caso de la comunidad autónoma de Murcia, España», Scripta Nova, vol. X, n 118 (90). http://www.ub.edu/geocrit/sn/ sn-218-90.htm 
CONSEJO DE EUROPA (2000): Convención Europea del Paisaje. Consejo de Europa.

CÓRDOBA, J. (2009): «Turismo, desarrollo y disneyzación: ¿una cuestión de recursos o de ingenio?», Investigaciones Geográficas, $\mathrm{n}^{\circ}$ 70, pp. 33-54.

DE ARANZABAL, I., SCHMITZ, M. F. y PINEDA, F. D. (2009): «Integrating landscape analysis and planning: A multi-scale approach for oriented management of tourist recreation», Enviromental Management, n 44 (5), pp. 938-951.

DIENER, P. (2007): «L'architecture de loisirs réinvente le paradis perdu», Espaces, $\mathrm{n}^{\circ}$ 248, pp. 9-13.

DOS SANTOS PIRES, P. (2011): «Marco teórico-metodológico de los estudios de paisaje. Perspectivas de aplicación en la planificación del turismo», Estudios y Perspectivas en Turismo, $\mathrm{n}^{\circ}$ 20, pp. 522-541.

FAUS PUJOL, M.C., y HIGUERAS ARNAL, A. (2000): «Turismo, paisaje y medio ambiente. Reflexiones geográficas», Geographicalia, nº 1 (Extra), pp. 9-24.

FERNANDEZ SALINAS, V. y SILVA PÉREZ, R. (2008): «El patrimonio y el territorio como activos para el desarrollo desde la perspectiva del ocio y del turismo», Investigaciones Geográficas, n 46, pp. 69-88.

FORONDA, C. y GALINDO, L. (2012): «Working with indicators: Description of states of territorial adjustment for protected natural areas», International Journal of Sustainable Development \& World Ecology, vol. 19, nº 4, pp. 287-296.

GALACHO JIMÉNEZ, F.B., y LUQUE GIL, A.M. (2000): «La dinámica del paisaje en la costa del sol desde la aparición del turismo», Baetica, $n^{\circ} 22$, pp. 25-58.

GÓMEZ AGUILERA, F. (2001): «Turismo y paisaje en Canarias: once apuntes contra las viejas formas», Basa, n 24, pp. 80-89.

GONZÁLEZ PÉREZ, J. ${ }^{\circ}$ M. (2003): «La pérdida de espacios de identidad y la construcción de lugares en el paisaje turístico de Mallorca», Boletín de la Asociación de Geógrafos Españoles, n 35 , pp. 137-152.

GOTTDIENER, M; SIMPSON, T. y SCHMID, H. (2010): Mega Tourist Metropolises: Las Vegas, Dubai and Macau. Contemporary Geographies of Leisure, Tourism and Mobility. Routledge, Taylor \& Francis Group.

HERNÁNDEZ RAMÍREZ, J. (2011): «Naturaleza a la carta. La retórica de la sostenibilidad turística y sus implicaciones en las políticas públicas en Andalucía», en Turismo y Patrimonio. Entramados narrativos. Colección Pasos. Revista de Turismo y Patrimonio Cultural, Tenerife, pp. 203-215.

JUNTA DE ANDALUCÍA (2012): La Estrategia de Paisaje de Andalucía. Una herramienta para la gobernanza del territorio. Documento Base para el primer debate interdepartamental. Junta de Andalucía.

LLURDES I COIT, J.C. (1994): «El turismo industrial y la estética de los paisajes en declive», Estudios Turísticos, n ${ }^{\circ} 121$, pp. 91-108.

MATA, R. y TARROJA, A. (Eds.) (2006): El paisaje y la gestión del territorio. Criterios paisajísticos en la ordenación del territorio y el urbanismo. Consorci Universitat Internacional Menéndez Pelayo de Barcelona, Centre Ernest Lluch y Diputació de Barcelona.

MERCADO, I. (2015): «Percepción y valoración social de los paisajes disfrutados: aportaciones desde el visitante para una gestión sostenible de espacios turísticos rurales. El caso de la Sierra de Aracena (Huelva)», Investigaciones Turísticas, n 9, pp. 160-183. 
MERINERO, R.; BETANZOS, J. M.; y DORADO, M. J. (2013): «La Estrategia de Turismo Sostenible en Andalucía: Elementos fundamentales en el marco de la planificación turística subregional andaluza», Revista de Estudios Regionales, nº 97, pp. 77-111.

MUÑOZ, F. (2006): «UrBAnalización: la huelga de los paisajes», en El paisaje y la gestión del territorio. Criterios paisajísticos en la ordenación del territorio y el urbanismo, MATA, R. y TARROJA, A. (Eds.). Consorci Universitat Internacional Menéndez Pelayo de Barcelona, Centre Ernest Lluch y Diputació de Barcelona, pp. 143-164.

NOGUÉ, J. (1992): «Turismo, percepción del paisaje y ordenación del territorio», Estudios Turísticos, $n^{\circ} 115$, pp. 45-54.

RAMÓN FERNÁNDEZ, F., y CANOS DAROS, L. (2010): «La sostenibilidad del turismo y la regulación protectora del paisaje valenciano», en Investigaciones, métodos y análisis del turismo, FERRARI, G. et al. (Eds.), Septem Ediciones, Oviedo, pp. 233-242.

RAMÓN FERNÁNDEZ, F. y CANOS DAROS, L. (2011): «Medidas de protección del paisaje para el turismo sostenible», en Renovación de destinos turísticos consolidados, LÓPEZ OLIVARES (Coord.), pp. 643-660.

REQUEJO LIBERAL, J. (2007): «La diferenciación y el reforzamiento de la identidad basados en la naturaleza, la cultura y el paisaje como factores de competitividad turística», Estudios Turísticos, no 172-173, pp. 115-120.

RODRIGUEZ CHUMILLAS, I. (2008): «Territorios del turismo. Paisaje urbanizado de la costa mediterránea», Topofilia, vol I, nº 1, pp. 1-39.

SÁNCHEZ DEL ÁRBOL, M.A. (2012): Acondicionamiento paisajístico de los accesos a las pequeñas poblaciones. Ensayo metodológico en el Valle de Lecrín (Granada). Centro de Estudios Paisaje y Territorio. Junta de Andalucía.

SCAZZOSI, L. (2004): «Reading and assesing the landscape a cultural and historical heritage», Landscape Research, vol. 29, n 4, pp. 335-355.

URRY, J. (2005): «The consuming of place», en Discourse, communication and tourism, JAWORSKI, A. y PRITCHARD, A. (eds.). Clevendon: Channel View, pp. 19-27.

VERA, F. (Coord.); LÓPEZ PALOMEQUE, F.; MARCHENA, M. y ANTÓN, S. (2011): Análisis territorial del turismo y planificación de destinos turísticos. Editorial Tirant Lo Blanch, Valencia.

ZUKIN, S. (1998): «Urban Lifestyles: Diversity and Standardisation in Spaces of Consumption», Urban Studies, vol. 35, no 5-6, pp. 825-839.

ZOIDO NARANJO F. y VENEGAS MORENO, C. (Coords.) (2002): Paisaje y Ordenación del Territorio. Consejería de Obras Públicas y Transportes, Junta de Andalucía y Fundación Duques de Soria, Sevilla. 